\title{
A propósito do gênero road movie no Brasil: um romance, uma série de TV e um filme de estrada
}

Samuel Paiva

\section{Resumo:}

No contexto dos problemas teóricos relacionados à definição dos gêneros audiovisuais, este artigo pretende contribuir para o debate ao tratar do road movie no Brasil, procurando suas interações entre cinema, televisão e literatura. A discussão tem início com o romance "Jorge, um brasileiro" (lançado em 1967), do escritor Oswaldo França Jr., texto que por sua vez deu origem ao filme homônimo (realizado em 1989), dirigido pelo cineasta Paulo Thiago, e à série de televisão "Carga pesada", produzida pela Rede Globo de Televisão (com temporadas intermitentes entre 1979 e 2007). A ideia é demonstrar como, no Brasil, as matrizes do road movie apresentam formulações muito distintas daquelas frequentemente reconhecidas no contexto dos Estados Unidos, país por vezes considerado como lugar de origem do gênero em questão.

\section{Palavras Chave:}

road movie; Brasil; cinema; literatura; televisão

\section{Abstract:}

This article contributes to the debate on the definition of movie and TV genres. It discusses road movies in Brazil, considering its interactions between movies, television and literature. This theme starts with the novel "Jorge, a Brazilian" (1967), written by Oswaldo França Jr. The book was adapted to the cinema in a homonymous film directed by Paulo Thiago (in 1989). A TV series called "Heavy Weight", produced by Globo Television Network (with discontinued seasons between 1979 and 2007) was also based on this novel. This article shows that road movies in Brazil have considerable differences if compared with its context in the United States of America, a country which is sometimes considered to be the birthplace of this movie genre.

\section{Keywords:}

road movie; Brazil; cinema; literature, television

\section{Introdução}

Alguns estudiosos dos gêneros audiovisuais têm apontado a dimensão local que os gêneros, em sua circulação mundial, adquirem de modo a revelar uma diversidade de possibilidades quanto a fatores que comumente estão atrelados a sua concepção: um texto codificado segundo padrões recorrentes; um público que espera reconhecer esses padrões e as suas variáveis; uma indústria que leva em conta os múltiplos interesses em jogo. A dimensão local das diversas experiências de produção e recepção audiovisuais, contudo, implica a relatividade de tais considerações. Assim, primeiramente, este trabalho procura problematizar alguns aspectos relacionados aos gêneros audiovisuais, tendo como parâmetro o road movie. O interesse em pauta volta-se para inflexões locais que podem pôr em xeque supostas matrizes - em geral, concebidas no contexto eurocêntrico - que em princípio definiriam características 
universais do gênero. Assim, são três os principais objetos de estudo. Primeiramente, há o romance Jorge, um brasileiro, do escritor mineiro Oswaldo França Jr. (lançado em 1967). Depois, há o filme homônimo adaptado da referida obra literária e realizado em 1989 pelo diretor também mineiro Paulo Thiago. E há a série de televisão Carga pesada, produzida pela Rede Globo, com uma primeira temporada veiculada de maio de 1979 a janeiro de 1981 e outras, apresentadas de 2003 a 2007.

Antes, contudo, das considerações sobre o romance, a série de TV e o filme, convém delimitar, ainda que resumidamente, a noção de gênero em pauta neste estudo. É possível afirmar que não há a rigor definições consensuais sobre o tema. Pelo contrário, existem na verdade "problemas de definição" (BERRY-FLINT, 1999: 26), na medida em que os gêneros são parte da produção e da recepção de filmes em todo o mundo, embora freqüentemente Hollywood seja considerada o ponto de partida dessa história, de onde os gêneros passariam a se reproduzir internacionalmente. Defende-se aqui, entretanto, que os sentidos relacionados aos gêneros audiovisuais são construídos em razão das especificidades locais, em um processo cuja complexidade envolve necessariamente histórias específicas, por mais que a circulação cada vez mais rápida dos produtos da indústria cultural tenha dimensões globalizadas.

De fato, essa posição é compartilhada por vários estudiosos do assunto. Sarah Berry-Flint (ibidem), por exemplo, considera os gêneros como discursos, campos culturalmente específicos de conhecimento que determinam o que pode ser pensado como ficção, notícia, entretenimento, história etc. Nesse sentido, em termos da circulação transnacional dos gêneros, ela propõe que sejam consideradas as especificidades dos diversos contextos.

Por sua vez, David Bordwell (2005: 295), estudando a narrativa no cinema clássico de Hollywood, referese à "lógica da espectatorialidade clássica" destacando diversas motivações, tais como as transtextuais (e aqui ele inclui também as convenções do gênero) e as motivações de gênero propriamente, cujos efeitos intervêm nos processos narrativos. Bordwell chega a afirmar que, de fato, a noção de cinema clássico é relativa, a depender do lugar em questão onde se dá a produção e a recepção, e reitera a importância do papel do espectador na construção do sentido do texto audiovisual por meio de seu processo de conhecimento, memória e cognição.

No Brasil, como acontece em outros países, o debate acerca dos gêneros tem lugar com perspectivas diversas, mas igualmente levando em consideração a dimensão local do problema. Entre outros, como exemplo, é oportuno lembrar os trabalhos de Ismail Xavier (2003) acerca do melodrama, em especial, sobre as adaptações das peças de Nelson Rodrigues para o cinema e para a TV. Outro exemplo são os estudos, mostras e seminários do grupo que propõe a noção de "cinema de bordas", interessando-se fortemente pelas produções de cineastas brasileiros amadores, como Seu Manoelzinho, Affonso Brazza, Simião Martiniano, Rambú da Amazônia, entre outros (SANTANA, 2008).

Mas, além dos pesquisadores citados até então, cabe destacar as proposições de Rick Altman (2000). O autor leva-nos a perceber o gênero como uma categoria útil, capaz de relacionar múltiplos interesses voltados a produtores, distribuidores, exibidores, público e críticos, considerando como aspecto fundamental as dimensões históricas da produção e da recepção aos filmes. Em tal perspectiva histórica, Altman chama a atenção para questões como: o hibridismo dos gêneros; as inúmeras possibilidades de periodizações de sua história; as referências intertextuais; a simplicidade como fator de linguagem simbólica; sua funcionalidade para produtores, espectadores e críticos; o interesse investido na cultura popular etc. Uma de suas considerações mais instigantes refere-se ao caráter "adjetivo" ou "substantivo" que pode ter um gênero em razão de seu momento histórico, com todos os fatores aí envolvidos (ibidem: 55-78). Como explica, exemplificando a questão, os primeiros musicais não eram considerados enquanto tal em seus primórdios, na transição do cinema silencioso para o sonoro. Naquela época, o termo musical era um adjetivo, um complemento utilizado para atribuir algum valor a um filme, que chamava a atenção 
por outros aspectos. Como substantivo, ou seja, como elemento definidor da obra cinematográfica, o termo musical só vai se consagrar posteriormente. Essa proposta de Altman para pensar o caráter adjetivo ou substantivo que pode ter um gênero em determinado momento de sua história permite uma ampla abertura para a compreensão, sobretudo, de objetos recentes ou ainda pouco estudados, como, por exemplo, os road movies e, eventualmente, algumas de suas variações, como os bike movies e os taxi movies.

Seguindo tais princípios, é presumível, portanto, que o caráter histórico dos gêneros, considerados em suas dimensões adjetivas ou substantivas, implique considerações sobre o road movie a partir de experiências diversas. Nesse sentido, é possível presumir que as matrizes brasileiras do road movie muitas vezes não se explicam segundo os padrões dos Estados Unidos, país considerado por muitos pesquisadores como o lugar de origem desse gênero.

David Laderman, por exemplo, uma importante referência no assunto, afirma que "o road movie surge como uma manifestação dinâmica da fascinação da sociedade americana pela estrada" (LADERMAN, 2002: 2) (1). A sociedade americana, no caso, refere-se eminentemente aos Estados Unidos. Ou seja, é possível que, ao construírem a história do gênero, alguns historiadores deixem de considerar a possibilidade de experiências diversas. Certamente por isso, aliás, Robert Stam (2003) critica o que chama de "hollywood-centrismo" recorrente nos estudos de gênero. Entretanto, novas tendências parecem despontar no horizonte. Jack Sargeant e Stephanie Watson (1999), por exemplo, embora reafirmem os Estados Unidos como lugar de origem do gênero, considerando-o herdeiro do western e dos filmes de juventude que explodem depois da Segunda Guerra Mundial, apontam para as possibilidades existentes em outros lugares.

A propósito, mais recentemente um número da revista Cinéma dedicado ao "road movie intercultural" traz análises sobre uma filmografia diversa, com títulos como $O$ céu que nos protege (Bernardo Bertolucci, 1990), Priscilla, a rainha do deserto (Stephan Elliott, 1994), Assassinos por natureza (Oliver Stone, 1994), A viagem (Fernando Solanas, 1992), Histórias mínimas (Carlos Sorín, 2002), Kandahar (Mohsen Makhmalbaf, 2001), entre outros. O organizador da edição, Walter Moser (2008: 7-30), mesmo reconhecendo os problemas de definição do gênero, propõe algumas matrizes deduzidas da observação de muitos filmes, que envolvem: imagens de um veículo em movimento, transportando seres humanos por uma estrada; uma iconografia relevante do veículo e da infra-estrutura que o faz funcionar; paisagens abertas, com poucas marcas de civilização; um protagonista em exílio acompanhado de uma segunda pessoa com quem forma um casal pelo menos durante uma parte do caminho; uma sequiência narrativa com três momentos de intensidade (pegar a estrada, estar na estrada, pegar a estrada novamente); uma modalidade narrativa que expressa a condição contingente do protagonista; uma interação de mídias que freqüentemente põe em cena o rádio instalado no veículo. Contudo, Moser admite variações sobre essa proposta, chamando a atenção para o fato de que inúmeros filmes que são considerados road movies não atenderiam a todos esses critérios. Seu cuidado é oportuno em termos conceituais, pois pressupõe atenção ao "multiculturalismo policêntrico", que justamente propõe uma reconsideração da História, inclusive das mídias, com parâmetros de resistência ao imperialismo eurocêntrico (SHOHAT \& STAM, 2006). Pressupõe igualmente a consideração pelo "world cinema", como propõe, entre outros, Lúcia Nagib, ao afirmar um cinema que não tem centro e que "como o próprio mundo, é circulação" (NAGIB, 2006: 35) (2).

\section{Jorge, um Brasileiro - o Romance}

Quando está em questão o gênero road movie, é provável que, para o Brasil, o romance Jorge, um brasileiro (lançado em 1967), de Oswaldo França Jr. (1988), tenha o mesmo valor paradigmático que tem On the road (lançado em 1957), de Jack Kerouac (2004), para os norte-americanos (3). De fato, assim 
como os personagens de Kerouac personificam os Estados Unidos da contracultura, o romance de França Jr. propõe também uma dimensão de "alegoria nacional" (cf. XAVIER, 2005: 339-379), ao projetar figuras que personificam uma nação, porém, a partir de outros parâmetros culturais. No prefácio à décima edição do romance de França Jr., as afirmações de Antônio Olinto sugerem o caminho das distinções: "Nesse relato de um grupo de pessoas se agitando num espaço, Jorge não é apenas Jorge, mas também um brasileiro". Está em questão, como diz, "o Brasil dos motoristas, o das estradas de rodagem, dos caminhões, das cidades que surgem, de realidades que avançam" (apud FRANÇA Jr., 1988: 16). Poderíamos acrescentar que está em questão, de fato, um Brasil de trabalhadores da estrada.

O tempo privilegiado da narrativa de França Jr. é a década de 1960, que começa com a inauguração de Brasília, tendo como outros marcos o Golpe Militar (1964) e o AI-5 (1968). À exceção da inauguração da "Novacap", contudo, nenhum desses fatos será mencionado durante a exposição dos acontecimentos, que são narrados por Jorge, em primeira pessoa, numa linguagem coloquial que submete a gramática à entonação de sua voz. O retrato da época aparece nas sutilezas das tramas com que se envolve o protagonista (diferentemente do que acontece no filme homônimo, como veremos mais adiante).

Jorge parte de Belo Horizonte, onde se situa a empresa de Mário, seu patrão, e precisa chegar a Caratinga (no interior de Minas Gerais), para resgatar, em uma semana, oito carretas carregadas de milho, as quais, devido às chuvas, estão paradas, pois as estradas estão em péssimas condições. Homem de confiança de Mário, Jorge tem por ele um grande respeito, considera-se seu amigo, apesar da exploração de que é vítima. A rigor, o romance pode ser visto como o despertar de sua consciência para a sua própria condição de explorado por um empresário corrupto. A ética, portanto, é um dos aspectos centrais do conflito apresentado no texto.

Enquanto empreende a tarefa de resgatar os caminhões, Jorge recordará vários episódios vividos em sua lida de trabalhador da estrada. Sem capítulos, a ação do romance segue um fluxo de consciência ao longo do qual o narrador, Jorge, conta a sua história, conectando fatos pela memória, empreendendo um juízo autocrítico de seu próprio papel e, ao mesmo tempo, um juízo crítico do papel do outro: o patrão, os colegas de trabalho, a sua namorada.

Associados aos obstáculos que o protagonista precisa superar, estão vários temas que revelam um Brasil que se moderniza, mas com muitos problemas. Nesse sentido, os veículos e as estradas são figuras fundamentais de um universo onde não faltam autoridades corruptas, onde a ausência do Estado impede o cuidado aos direitos do cidadão, onde há menores marginalizados, crimes ambientais, trabalho escravo, violência contra os índios, entre tantas outras mazelas. Nesse quadro, Jorge impõe-se como um trabalhador cioso de sua função de conduzir outros trabalhadores que, sob suas ordens, devem conduzir seus caminhões da melhor maneira possível, cumprindo com os contratos do patrão. O trabalho é, portanto, o aspecto central do romance. Com o seu trabalho, Jorge ajudou o patrão a enriquecer, como recorda:

Quando o senhor Mário trocou a oficina de Volkswagem pelos cinco caminhões, me chamou e mostrou os cinco. E estavam todos enguiçados. Apenas dois estavam andando. Mas, desses dois, um não rodava a caçamba, e o outro não pegava no arranque nem se você ajuntasse cinqüenta baterias uma atrás da outra e ligasse tudo no motor. [...] E eu, então, saí para a rua e vou dizer para você que nunca trabalhei tanto para colocar cinco carros em condições de funcionar (FRANÇA Jr., 1988: 24-25).

Se por um lado Jorge atende ao interesse do patrão, por outro, o trabalho faz com que ele entre em crises sucessivas com a sua namorada Sandra e com os seus companheiros no transporte das cargas. Mas na medida em que o seu esforço não é valorizado por Mário, o empresário que lhe impõe tarefas impossíveis 
enquanto aproveita a vida ao lado da amante, Jorge rompe o vínculo com o patrão e parte para viver outra história. Antes disso, ao longo do romance, ele reflete sobre a sua condição:

E eu pensando comigo que eu nunca tinha tido uma casa minha mesmo para morar. E que se fosse contar, ia ver que, depois que comecei a trabalhar para o senhor Mário, tinha morado mais tempo em barraca e cabina de caminhão, do que em casa, ou barracão, ou garagem, ou escritório. E que nunca também tive lugar certo para morar muito tempo (ibidem: 54).

Ou seja, o caráter outsider de Jorge está definido a partir de parâmetros muito distintos daqueles que movem a jornada de personagens como Sal Paradise e Dean Moriarty, em On the road, que, como diz Eduardo Bueno (tradutor do romance no Brasil), "está vinculado, desde o advento daquele movimento [hippie], aos mais variados e desvairados desatinos cometidos na década de 60" (apud KEROUAC, 2004: 8). Jorge tampouco nos faz recordar filmes como Bonnie and Clyde (Arthur Penn, 1967) ou Easy rider (Dennis Hopper, 1969), considerados marcos inaugurais e formuladores das principais tendências do gênero nos Estados Unidos. O universo de Jorge, um brasileiro é outro. É herdeiro de uma tradição modernista brasileira que registra a geografia de um país onde personagens se deslocam tentando a sobrevivência, em busca de trabalho. Graciliano Ramos e Jorge Amado poderiam ser aqui evocados como referências de uma criação literária fortemente marcada por um viés de crítica social preocupada com a carência de setores diversos da sociedade brasileira. Não por acaso, aliás, foi Jorge Amado quem escreveu o prefácio de Jorge, le camionneur, título com que o romance de Oswaldo França Jr. foi lançado na França.

\section{Carga Pesada - a Série de TV}

A série Carga pesada foi produzida pela Rede Globo, com algumas interrupções, no intervalo 19792007. Contava no elenco principal com os atores Antonio Fagundes e Stênio Garcia vivendo, respectivamente, os papéis de Pedro e Bino. Uma primeira temporada da série foi veiculada de maio de 1979 a janeiro de 1981, às terças-feiras, às 22 horas (cada episódio com aproximadamente uma hora de duração). Nesse primeiro momento, Carlos Queiroz Telles, Gianfrancesco Guarnieri e Walter George Durst integravam a equipe de criação. Os textos eram supervisionados por Dias Gomes e a direção geral estava sob a responsabilidade de Daniel Filho. Antonio Fagundes recorda como a história da série começou:

Pois é, você sabe que todas as coisas que são muito longas assim acabam criando lendas. [...] Mas a lenda que eu me lembro é que a gente fez na Globo um programa chamado Estúdio A, que era um programa semanal de teleteatro. E o Paulo José fez uma adaptação de um livro do Oswaldo França Jr., chamado Jorge, um brasileiro. [...] O Daniel [Filho] tava criando as séries brasileiras. E ele já tinha o Malu, mulher, que foi a primeira série que ele criou. Depois parece que tinha o Plantão de polícia também. Faltava um programa para completar as séries brasileiras e o Paulo [José] deu a idéia de que fosse alguma coisa de carreteiro (4).

Interrompida em 1981, a série volta ao ar em abril de 2003, sendo veiculada às sextas-feiras à noite, com novas temporadas em 2004, 2005, 2006, até setembro de 2007, quando foi exibido o último episódio. Nessas novas temporadas, a direção geral esteve a cargo de Roberto Naar, que eventualmente dividia responsabilidades com colegas como Marcos Paulo e Ary Coslov. Vários episódios foram escritos por duas mulheres, Ecila Pedroso e Mara Carvalho, mas o time de roteiristas contava também com o próprio Antonio Fagundes, além de Leopoldo Serran, Geraldo Carneiro, entre outros (5).

Desde o início, contudo, a série é marcada (assim como o romance de França Jr. e o filme de Paulo Thiago) por um esforço de se constituir como alegoria nacional. No episódio Enchente (veiculado em 
19/06/1979), por exemplo, é utilizada uma estratégia de inserção, em meio à ficção, de matérias jornalísticas produzidas pela própria Globo a propósito de enchentes decorrentes da chuva e também da infra-estrutura rodoviária precária do país. Já as temporadas mais recentes - a partir de 2003 - são produzidas em cores, com destaque para o verde e o amarelo da vinheta de abertura retomando a músicatema $\mathrm{O}$ frete, composição de Renato Teixeira, que tampouco deixa dúvida quanto ao caráter desbravador e conhecedor da realidade do país que cabe aos protagonistas.

Eu conheço cada palmo desse chão / E só me mostrar qual é a direção / Quantas idas e vindas / Meu Deus quantas voltas / Viajar é preciso é preciso / Com a carroceria sobre as costas / Vou fazendo o frete cortando o estradão / Eu conheço todos os sotaques / Desse povo todas as paisagens / Dessa terra todas as cidades / Das mulheres todas as vontades / Eu conheço as minhas liberdades / Pois a vida não me cobra o frete...

O frete é a causa que move os personagens nas diversas narrativas dos vários episódios. É a razão da vida enquanto sobrevivência tanto dos caminhoneiros quanto daqueles que deles dependem. E aqui é preciso discutir a dimensão que a família e a vida doméstica têm nas histórias de Pedro e Bino. Pedro, quando recém-nascido, foi encontrado na boléia de um caminhão, decorrendo daí o seu apelido: Pedro da Boléia (no episódio Carga perecível, aliás, Pedro e Bino também se depararam com uma criança que foi deixada em seu caminhão). Adotado por um velho caminhoneiro e sua esposa, o menino aprendeu com o pai adotivo a dominar as estradas. Quando adulto, sai viajando pelo país afora na companhia de Bino e recusa-se a constituir uma família, defendendo em vez disso a sua liberdade. A propósito, tenta conquistar todas as mulheres que encontra pelo caminho, sem se comprometer com nenhuma delas. Pedro se autodefine (no episódio Caminhos cruzados) como "o que de mais longe pode existir de um porto seguro". Entretanto, encontra no amigo Bino o seu "irmão".

Por sua vez, Bino é muito diferente de Pedro. Casado com Dadá, ele tem filhos e, por conta da vida de caminhoneiro, só vê a família de tempos em tempos, situação que gera muitas crises familiares (como no episódio A suspeita, em que ele desconfia de uma possível traição de sua mulher, que estaria envolvida com outro homem). Contudo, assim como Bino, Dadá é fiel, mas infeliz, e acaba morrendo. Com a morte de sua esposa, Bino segue pela estrada, viúvo, ao lado do companheiro Pedro. Na verdade, a morte de Dadá está relacionada à crise familiar, decorrente da permanente ausência do marido.

Estamos, portanto, diante de uma possível matriz do road movie, ou seja, uma crise da unidade familiar que constitui um motor no avançar dos protagonistas pela estrada. Entretanto, o movimento de recusa ao universo doméstico está justificado não por uma oposição à casa dos familiares (como acontece com os personagens de Kerouac). Pelo contrário, decorre de uma afirmação dos valores familiares. É para manter sua família que Bino se mantém na estrada, trabalhando. Mas, ao mesmo tempo e paradoxalmente, é o trabalho como caminhoneiro que justifica a sua distância em relação à mulher e aos filhos. Talvez o exemplo mais enfático do contraditório respeito de Bino pela dimensão estável da vida burguesa esteja relacionado à sua dificuldade para aceitar a decisão do seu primogênito, Pedrinho (Wagner Moura), quando este, no quarto ano de Medicina, resolve desistir da universidade para se tornar caminhoneiro, como o pai (situação que se constitui como conflito em vários episódios, por exemplo, Caminhos cruzados e Carga perecível). Em suma, à mulher e aos filhos, não se permite o desprendimento que só é possível para homens adultos. Entretanto, a imagem do lar permanece na cabeça desses viajantes, "profanando" o seu "tino forte de homem", como revela a música $O$ frete:

Mas quando me lembro lá de casa / A mulher e os filhos esperando o pão / Sinto que me morde a boca da saudade / E a lembrança me agarra e profana / O meu tino forte de homem / E é quando a estrada me acode... 
Em tal concepção, o espaço característico do homem é a rua, em detrimento da casa, embora haja entre a casa e a rua uma forte e desconcertante relação. A propósito, é oportuno recordar nesse ponto um estudo de Roberto DaMatta (1997), no qual a casa e a rua são trabalhadas como categorias sociológicas relacionais. Como afirma o antropólogo, tais espaços "contêm visões de mundo ou éticas particulares" (ibidem: 47) que estabelecem tensões entre si. O espaço da casa, que lembra casal, casamento, associa-se ao amor, ao carinho, à familiaridade, à hospitalidade. Por sua vez, a rua é o lugar onde, em vez da afetividade, prepondera o código da lei, com seus mecanismos impessoais. A rua é o espaço dos perigos, das aventuras, das arruaças e dos arruaceiros, das pessoas anônimas, sem família. A rua é o local de todos os perigos próprios do espaço público. Mas "na gramaticidade dos espaços brasileiros, rua e casa se reproduzem mutuamente" (ibidem: 54). Nesse sentido, é oportuno observar como Pedro e Bino de uma certa forma substituem a casa original pelo caminhão, onde explicitam seu afeto mútuo, de um pelo outro, construído com laços de fraternidade entre dois amigos que muitas vezes mais parecem um casal, ainda que negando veementemente qualquer perspectiva homossexual, o que se confirma não só por sua atração reiterada pelas mulheres (especialmente no caso do conquistador Pedro da Boléia) como também pelas piadas homofóbicas que vêm à tona, vez por outra, em seus diálogos, questão colocada de forma mais complexa no romance de França Jr., a partir do personagem Toledo.

A propósito, muitos temas do livro são retomados na série de TV, que, entretanto, cria novas situações: atenção ao nascimento de bebês, defesa da formação escolar, crítica ao trabalho infantil, recuperação de menores delinqüentes, resistência ao tráfico e às drogas (inclusive ao rebite utilizado pelos caminhoneiros), cuidados com a saúde, cobrança dos órgãos públicos quanto aos seus deveres junto à população, defesa do meio ambiente, proteção aos índios. Todos esses são temas que, em vários episódios, confirmam o interesse da série em uma afirmação de um projeto nacional no qual os valores privados e públicos se misturam na relação entre a casa e a rua.

Em Carga pesada (e também no livro de Oswaldo França Jr. e no filme de Paulo Thiago), de fato, tal envolvimento entre a casa e a rua, de um modo que instaura o caminhão como um espaço um tanto intermediário, confirma a ambigüidade apontada por DaMatta ao tratar da perspectiva relacional entre os dois espaços como característica das culturas herdeiras do catolicismo ibérico, como é o caso da cultura brasileira. Há aqui, como afirma o autor, um esforço de fazer incluir, convergir, relacionar lados opostos, uma característica fundamental do sistema social constituído no Brasil. Estaria aí nesse ponto um "traço distintivo em oposição a outros sistemas, sobretudo os que informam os valores das nações protestantes, como os Estados Unidos" (ibidem: 108).

\section{Jorge, um Brasileiro - o Filme}

Já o diretor Paulo Thiago problematiza esse caráter conciliador próprio da cultura brasileira destacando a confusão entre amizade e trabalho, a partir do vínculo entre Jorge, o empregado (interpretado por Carlos Alberto Riccelli), e Mário, o patrão (vivido pelo americano Dean Stockwell, dublado nas cópias produzidas para o Brasil). Em relação ao romance de França Jr., este é um aspecto mais enfatizado no roteiro do próprio Paulo Thiago e de Alcione Araújo. No filme, Jorge não se refere ao seu patrão tão respeitosamente como "senhor Mário": a distância entre os dois é bem menor. A adaptação do texto literário ao fílmico, como previsto, opera vários deslocamentos. A dimensão de alegoria nacional, por exemplo, permanece como um dado essencial, mas agora parte do momento referente ao governo Médici (1969-1974), cujo nome está registrado em uma placa fincada na Rodovia Transamazônica, já nas sequências iniciais do filme, chegando até a época de José Sarney como presidente da República (19851990), cuja foto está fixada em uma cena ambientada em uma delegacia de polícia, quase ao final do longa-metragem. 
Em relação ao livro, o discurso do filme é mais didático, no sentido de não deixar dúvidas quanto às suas intenções alegorizantes. Os créditos iniciais, por exemplo, vêm com letras amarelas sobre fundo verde (6). Já a empresa, que tinha "o nome do senhor Mário escrito nas portas" (FRANÇA Jr., 1988: 26), transforma-se no filme em Transportadora Brasil S.A. Carlos Alberto Riccelli, como ator, tem uma entonação mais classe-média, condizente com a atual ambição do personagem de se tornar empresário, se conseguir arrematar um lote de caminhões a ser leiloado pela prefeitura. Para tanto, Jorge precisa da ajuda do amigo-patrão. Mário lhe promete o apoio, mas, enquanto o caminhoneiro vai resgatar as carretas para trazê-las de volta a tempo para a inauguração da refinaria do governo federal, o empresário arremata para si próprio o lote com os veículos. Está em pauta o papel de um pequeno para médio empresariado nacional que emerge no milagre econômico.

Como contraponto, há a figura de Altair (Roberto Bonfim), que também começou como caminhoneiro, mas deixou de trabalhar para aquele que primeiro se tornou empresário (Mário) e criou o seu próprio negócio - uma oficina de carros -, estabelecendo-se com casa, esposa (Denise Bandeira) e filhos. Jorge o procura, pedindo ajuda para o resgate das carretas. E obtém de Altair a ajuda esperada de forma desinteressada, em nome da amizade.

São essas parcerias que para o bem ou para o mal serão fundamentais aos rumos do país. Nesse sentido, uma cena representativa é a do atropelamento, em Brasília, à noite. No livro, Jorge abandona sua vítima e foge para apagar as marcas do acidente deixadas no caminhão. No filme ocorre o mesmo, porém, ele confessa o crime ao amigo-patrão, que se dispõe a recorrer aos poderosos que utilizarão sua influência política para resolver a situação, sem que Jorge tenha que assumir a responsabilidade pelo acontecido.

Como personificação de uma nação, Jorge tem diante de si a percepção de um sistema corrompido diante do qual precisa se posicionar, a favor ou contra, para seguir adiante. E ele tem alguns parâmetros como exemplos, como prova a cena do bêbado que pergunta "qual é o maior homem do mundo". No livro, a resposta é Juscelino Kubitschek, o filho de caixeiro-viajante, prefeito de Belo Horizonte (1940-1945), governador de Minas Gerais (1951-1955) com o lema "energia e transporte", presidente da República (1956-1961) com sua idéia desenvolvimentista de "cinqüenta anos em cinco", quando ocorre a construção de Brasília e consolida-se a implantação da indústria automobilística no Brasil. No filme, a resposta é Tancredo Neves, o homem que, com uma vasta história de político brasileiro, associa-se ao imaginário nacional vinculado às Diretas Já e ao processo de redemocratização do país.

O filme trabalha didaticamente com estas duas possibilidades: o bem associado à liberdade e ao processo democrático; o mal vinculado à ditadura e suas heranças. $\mathrm{O}$ protagonista transitará de um pólo ao outro até se definir efetivamente. A propósito, o filme inclui cenas que configuram um momento da nação em que há embates vividos por trabalhadores rurais, posseiros e pelos próprios caminhoneiros contra policiais fardados, fazendeiros e seus capangas. Jorge, impedido por um policial de ultrapassar uma barreira na estrada, decide enfrentá-lo e avança com o seu caminhão, em uma seqüência que traz um espetacular cavalo-de-pau da carreta carregada com algumas toneladas de milho. Mesmo a chuva assume no texto fílmico um viés político, ao ser associada ao desequilíbrio ecológico. Os rádios dos caminhões trazem notícias sobre os buracos na camada de ozônio, enquanto se sucedem planos de chuva, lama, casas e carros inundados, postes caídos, pontes destruídas, o que resulta, como diz o rádio, em centenas de mortos.

A decisão diante da escolha a ser feita em termos de um projeto nacional envolve tanto os empresários quanto os trabalhadores. "Esse prazo que o Mário inventou é impossível de cumprir" - diz Fefeu (Antonio Grassi), caminhoneiro que se impõe contra o patrão e o seu homem de confiança. Mas sendo uma liderança, Jorge conseguirá dobrar a resistência de Fefeu, assim como a dos demais caminhoneiros, convencendo-os a seguir com o impossível plano de resgate das carretas. Mas chegará o momento em que 
o protagonista alcançará uma consciência de classe, entendendo, como Fefeu, que "problema de patrão é de patrão, eu sou empregado".

Nesse aspecto, cabe observar que a série Carga pesada coloca a questão do trabalho sobre termos mais complexos, uma vez que Pedro e Bino são autônomos, donos do seu próprio caminhão e, enquanto tal, geradores de sua própria força de trabalho na pequena empresa. Já o desejo de Jorge seria colocar-se no lugar do patrão: ele vai à casa de Mário, senta-se em seu sofá e tem relações sexuais com Helena (Imara Reis), a esposa do empresário. Algo, contudo, indica que sua consciência pode se transformar, como sugere sua resistência à violência na cena, inspirada na decupagem do western, na qual ele e Mário se confrontam. Ou como indica a canção Visões, de Túlio Mourão e Ronaldo Bastos, cantada por Milton Nascimento: "Daqui para frente vai só, não vira o rosto para trás, celebra o sol que se levanta, canta, canta, sonhador" (7).

\section{O trabalho}

No âmbito da cultura brasileira, como se observa no romance Jorge, um brasileiro, no filme homônimo de Paulo Thiago e na série Carga pesada, prevalecem certos valores relacionados, sobretudo, ao trabalho de motorista, numa perspectiva que difere bastante daquela dos road movies produzidos no contexto eurocêntrico. É provável, aliás, que a dimensão do trabalho, aspecto verificado nos objetos aqui debatidos, seja reconhecível em outros produtos de mídia realizados no Brasil dentro da perspectiva do road movie, como a primeira série da televisão brasileira, $O$ vigilante rodoviário (que estreou na TV Tupi, em 1961), e a mais recente Faça sua história (TV Globo, 2008), por exemplo, além de vários filmes do cinema nacional. Tais análises ficarão, contudo, para outro momento. Por ora, acerca dos objetos apresentados, cabe ainda destacar a relevância de Minas Gerais, quando está em pauta uma história do road movie no Brasil.

\section{Bibliografia:}

ALTMAN, Rick. Los gêneros cinematográficos. Trad. Carlos Roche Soárez Barcelona, Buenos Aires: Paidós, 2000.

BERRY-FLINT, Sarah. “Genre”. In: MILLER, Toby; STAM, Robert (eds.). A companion to film theory. Oxford, UK: Blackwell Publishing, 1999, pp. 25-44.

BORDWELL, David. “O cinema clássico hollywoodiano: normas e princípios narrativos”. In: RAMOS, Fernão (org.). Teoria contemporânea do cinema: documentário e narratividade ficcional, vol. 2. São Paulo: Senac, 2005, pp. 277-301.

BUSCOMBE, Edward. "A idéia de gênero no cinema americano". In. RAMOS, Fernão (org.). Teoria contemporânea do cinema: documentário e narratividade ficcional, vol. 2. São Paulo: Senac, 2005, pp. 303-318.

DaMATTA, Roberto. A casa \& a rua: espaço, cidadania, mulher e morte no Brasil. Rio de Janeiro: Rocco, 1997.

FRANÇA Jr., Oswaldo. Jorge, um brasileiro. 10ª . ed. Rio de Janeiro: Nova Fronteira, 1988.

LADERMAN, David. Drive visions: exploring the road movie. Austin: University of Texas Press, 2002. 
KEROUAC, Jack. On the road: Pé na estrada. Trad. Eduardo Bueno. Porto Alegre: L\&PM, 2004.

MOSER, Walter. "Présentation. Le road movie: un genre issu d'une constellation moderne de locomotion et de médiamotion”. In: Cinéma, vol. 18, no 2-3, Québec: Univ. du Montréal, 2008, pp. 7-30.

NAGIB, L. "Toward a positive defenition of world cinema". In: DENNISON, S.; LIM, S.H. Remapping world cinema: identity, culture and politics in film. London, New York: Wallflower Press, 2006, pp. 3037.

SANTANA, Gelson (org.). Cinema de bordas 2. São Paulo: Editora a Lápis, 2008.

SARGEANT, Jack; WATSON, Stephanie (eds.). Lost highways: an illustrated history of road movies. UK: Creation Books, 1999.

SHOHAT, Ella; STAM, Robert. Crítica da imagem eurocêntrica: multiculturalismo e representação. Trad. Marcos Soares. São Paulo: Cosac Naify, 2006.

STAM, Robert. "Alguns interrogantes sobre autoria e gênero". In: Introdução à teoria do cinema. Trad. Fernando Mascarello. Campinas: Papirus, 2003, pp. 144-151.

XAVIER, Ismail. O olhar e a cena: melodrama, Hollywood, Cinema Novo, Nelson Rodrigues. São Paulo: Cosac \& Naify, 2003.

XAVIER, Ismail. “A alegoria histórica”. In RAMOS, Fernão Pessoa (org.). Teoria contemporânea do cinema: pós-estruturalismo e filosofia analítica. São Paulo: Editora Senac, 2005, pp. 339-379.

\section{Notas:}

Uma versão anterior deste texto foi apresentada no XVIII Encontro da Compós, ocorrido na PUC-MG, em Belo Horizonte, em junho de 2009.

(1) No texto original: "The road movie appears as a dynamic manifestation of American society's fascination with the road".

(2) No texto original: "Word cinema is simply the cinema of the world. It has no centre, but it is us. It has no beginning and no end, but is a global process. World cinema, as the world itself, is circulation".

(3) Segundo informações contidas na contracapa da $10^{a}$. edição do livro Jorge, um brasileiro, lançada em 1988 pela editora Nova Fronteira: "Oswaldo França Júnior nasceu na cidade do Serro, Minas Gerais. [...] Aos dezessete anos ingressou na Força Área Brasileira indo para a Escola Preparatória de Cadetes, em Barbacena, e depois para o Curso de Formação de Oficiais Aviadores no Campo dos Afonsos, no Rio de Janeiro. [...] Por ocasião do movimento militar de 1964 foi afastado da Aeronáutica sob acusação de subversivo. Casado, pai de três filhos, ao ver-se proibido de exercer atividades ligadas à aviação passou a realizar vários trabalhos e dedicar-se à literatura..." (apud FRANÇA Jr., 1988). Oswaldo França Jr. morreu em 1989, vítima de um acidente de automóvel.

(4) Depoimento de Antonio Fagundes contido nos extras da caixa de DVDs do Carga pesada lançada pela Globo Marcas em 2006. Cabe observar que as considerações apresentadas neste trabalho acerca da série em questão resultam da observação de alguns episódios contidos na caixa, em especial, Enchente 
(veiculado em 19/06/1979), A suspeita (17/07/1979), Arapuca (21/08/1979), Caminhos cruzados (12/08/2003), Carga perecível (02/09/2003), Companheiros (16/09/2003), Homem não chora (30/04/2004), Entre sombras (14/05/2004), Estrada.com.br (28/05/2004), O lobisomem (13/08/2004), Arara una (08/04/2005) e O corno sou eu (15/04/2005).

(5) Cabe notar que Geraldo Carneiro é um dos criadores da série Faça sua história (2008), também produzida pela Rede Globo, trazendo as aventuras do taxista Oswaldir (vivido pelo ator Vladimir Brichta), com narrativas que em alguma medida retomam aspectos de Carga pesada, principalmente ao explorar a profissão de motorista do protagonista.

(6) Algumas informações trazidas nos créditos originais: no elenco estão Carlos Alberto Riccelli, Gloria Pires, Dean Stocowell, Denise Dummond, Roberto Bonfim, Denise Bandeira, Imara Reis, Antonio Grassi, entre outros. São produtores associados: Encontro, Embrafilme, Skylight, Transvídeo. Produtores executivos: Jane Guerra Peixe, Carlos Moletta. Direção de arte: Clovis Bueno. Montagem: Gilberto Santeiro. Direção de fotografia: Antonio Meliande. Música: Túlio Mourão. Canção "Visões", de Túlio Mourão e Ronaldo Bastos, cantada por Milton Nascimento. Roteiro: Alcione Araújo e Paulo Thiago. Produção: Glaucia Carmargos.

(7) Como dado complementar, cabe notar que o filme fez um grande sucesso de bilheteria no Brasil, com mais de um milhão de espectadores em 1989. Além disso, circulou por mais de trinta países em sua versão em inglês, segundo depoimento do diretor Paulo Thiago, nos extras do DVD de Jorge, um brasileiro, lançado pela Paramount Brasil.

\section{Mini Currículo :}

Professor adjunto da Universidade Federal de São Carlos (UFSCar), na área de História e Teoria do Audiovisual. E-mail: samuelpaiva@ufscar.br. 